\title{
Community reintegration following holistic milieu-oriented neurorehabilitation up to 30 years post-discharge
}

\author{
Ramaswamy Kavitha Perumparaichallai ${ }^{\mathrm{a}}$, Rivian K. Lewin ${ }^{\mathrm{a}, \mathrm{b}}$ and Pamela S. Klonoff ${ }^{\mathrm{a}, *}$ \\ ${ }^{a}$ Center for Transitional Neuro-Rehabilitation, Barrow Neurological Institute/St. Joseph's Hospital \\ and Medical Center, Phoenix, AZ, USA \\ ${ }^{\mathrm{b}}$ Department of Psychology, University of Memphis, Memphis, TN, USA
}

\begin{abstract}
.
BACKGROUND: The primary goal of neurorehabilitation for individuals with acquired brain injury (ABI) is successful community reintegration, which commonly focuses on home independence, productivity, and social engagement. Previous research has demonstrated that holistic treatment approaches have better long-term outcomes than other treatment approaches. Holistic approaches go beyond the fundamental components of neurorehabilitation and address metacognition and selfawareness, as well as interpersonal and functional skills.

OBJECTIVES: The present study aimed to examine community reintegration of individuals with ABI who completed holistic milieu-oriented neurorehabilitation at the Center for Transitional Neuro-Rehabilitation (CTN), Barrow Neurological Institute (BNI) at up to 30-years post-discharge. We evaluated (a) functional independence, (b) productivity and driving status, and (c) psychosocial profiles of the brain injury survivors.

METHOD: Participants included 107 individuals with ABI with heterogeneous etiologies who attended holistic milieuoriented neurorehabilitation between 1986 and 2016. These participants completed the Mayo-Portland Adaptability Inventory4 (MPAI-4) and a long-term outcome questionnaire (LOQ) specifically developed for this study.

RESULTS: The results demonstrate that $89 \%$ of participants were productive at up to 30 years post-discharge (73\% engaged in competitive work and/or school) after excluding the retired participants. Almost all of the participants who were engaged in work and/or school reported using compensatory strategies on a long-term basis. Furthermore, only $14 \%$ out of 102 study participants were driving at the time of program admission; whereas $58 \%$ out of 96 were driving at the time of discharge; and impressively, $70 \%$ out of 107 participants were driving at the time of follow-up. Regression analyses revealed that older age at the time of injury, shorter duration between injury and treatment, and better functionality indicated by lower MPAI-4 Ability Index scores significantly predicted a return to driving status at the time of study participation. Psychosocial data from the LOQ revealed positive findings with respect to patients' marital status, living situation, income, and quality of social life.

CONCLUSION: The findings from this study suggest that functional gains made during holistic neurorehabilitation have enduring effects and that patients can benefit highly from holistic milieu therapy beyond the early post-acute phases of their recovery. Additionally, they provide evidence that there is potential to return to driving, years after treatment completion.
\end{abstract}

*Address for correspondence: Pamela S. Klonoff, 222 W Thomas Road, Suite 401, Phoenix, AZ 85013, USA. E-mail: Pamela. Klonoff@dignityhealth.org. 
Our holistic milieu treatment approach addressing metacognition, self-awareness, social and coping skills training, and actively transitioning to community settings, is thought to have contributed to the exceptional and long-lasting outcomes in this study.

Keywords: Holistic neurorehabilitation, long-term outcome, traumatic brain injury, acquired brain injury, return to work, return to driving, community reintegration

\section{Introduction}

The primary goal of neurorehabilitation is to enhance the community reintegration of individuals with acquired brain injuries (ABI). Three common treatment domains of community reintegration are (a) management of independent living tasks, (b) engagement in productive activities (e.g., employment, school, or volunteer work), and (c) participation in social activities (Andelic et al., 2016; Arwert et al., 2017; Malec \& Kean, 2016; Sander, Clark, $\&$ Pappadis, 2010). Holistic neurorehabilitation programs accomplish these goals by (a) integrating treatment of cognitive, emotional, interpersonal, and functional skills, (b) addressing metacognition (i.e., self-awareness and self-appraisal) to set realistic goals, (c) providing individual and group therapies, and (d) enabling individuals with brain injuries to lead meaningful lives despite their persisting deficits (Cicerone et al., 2008; Klonoff, 2010).

It is well-documented that comprehensive, holistic neurorehabilitation is an effective treatment for improving community reintegration (Cattelani, Zettin, \& Zoccolotti, 2010; Cicerone et al., 2019; Cicerone et al., 2011). A number of outcome studies have demonstrated the benefits of holistic neurorehabilitation in facilitating a systematic and safe return to driving (Klonoff et al., 2006; Klonoff et al., 2010; León-Carrión, Domínguez-Morales, \& Martin, 2005; Olver, Ponsford, \& Curran, 1996; Perumparaichallai, Husk, Myles, \& Klonoff, 2014) and enhancing productivity (Cicerone et al., 2019; Cicerone et al., 2011; Cicerone et al., 2008; Klonoff et al., 2007, Sarajuuri et al., 2005) after ABI. Moreover, this evidence also suggests higher rates of return to driving the longer the follow-up duration (Klonoff et al., 2006, Olver et al., 1996). Additionally, studies show positive outcomes in aspects of psychosocial functioning, including interpersonal relationships (Klonoff et al., 2006; Olver et al., 1996), independent living status (Geurtsen, Martina, van Heugten, \& Geurts, 2008; Geurtsen et al., 2011; Klonoff et al., 2006; Malec, 2001), financial independence (Klonoff et al., 2006), societal participation (Geurtsen et al., 2011), and satisfaction in overall quality of life (Cicerone et al., 2008; Geurtsen et al., 2008; Geurtsen et al., 2011).

Research has shown that individuals with $\mathrm{ABI}$ who receive treatment earlier (i.e., within one year post-injury) make significantly more progress in community reintegration than those who participate later (i.e., more than one year post-injury) (Cicerone et al., 2019; Hayden et al., 2013; León-Carrión, Machuca-Murga, Solís-Marcos, León-Domínguez, \& Domínguez-Morales, 2013; Malec \& Kean, 2016). At the same time, it is indisputable that some individuals who participated in neurorehabilitation even after two or more years post-injury demonstrated clinically significant progress in achieving their community reintegration goals (High, Roebuck-Spencer, Sander, Struchen, \& Sherer, 2006; Hylin, Kerr, \& Holden, 2017; Kleim \& Jones, 2008; Trudel, Nidiffer, $\&$ Barth, 2007).

Long-term outcome studies illustrate gains, yet the impact of persisting deficits after ABI on community reintegration (Colantonio et al., 2004; Forslund et al., 2019; Ponsford et al., 2014). In the literature, long-term holistic neurorehabilitation outcome studies are limited to two years (Sarajuuri et al., 2005), five years (Olver et al., 1996), seven years (Klonoff et al., 2006), or maximum 11 years post-discharge (Klonoff, Lamb, \& Henderson, 2000; 2001). The present study expanded the follow-up interval compared to previous studies and assessed the status of productivity, driving, and quality of life among individuals with ABI. A better understanding of a long-term extended outcome after moderate to severe brain injury can yield better insights for critical elements of post-acute neurorehabilitation programs.

The specific aim of the present study was to explore community reintegration among individuals with ABI who completed holistic milieu-oriented neurorehabilitation up to 30 years ago. We examined: (a) productivity status; (b) driving status; (c) 
psychosocial functioning; and (d) variables that predicted a successful return to driving and work.

\section{Methods}

\subsection{Setting}

The CTN is a holistic milieu-oriented outpatient neurorehabilitation program that has been in operation since 1986. It was originally called the Adult Day Hospital for Neurorehabilitation (ADHNR); the name was changed in 1993.

\subsection{Participants}

Participants included 107 individuals with ABI (i.e., heterogeneous neurological etiologies) who attended holistic milieu-oriented neurorehabilitation between 1986 and 2016. They completed one or more of the following neurorehabilitation interventions to facilitate: (a) home and community independence, (b) social relationships and quality of life, (c) work re-entry, and/or (d) school re-entry.

\subsection{Intervention}

All of the treatment programs included individual and group therapies addressing physical, cognitive, language, interpersonal, and emotional deficits employing a combination of multidisciplinary, interdisciplinary, and transdisciplinary approaches (Klonoff, 2010; 2015). The multidisciplinary team consisted of the following therapeutic specialties: neuropsychology; speech-language pathology; occupational therapy; physical therapy; and recreational therapy. Survivors of ABI also received services in the areas of psychiatry and nutrition, as appropriate. Typical treatment frequency included clinic-based therapies three to five days per week, four to six hours per day. As treatment progressed, interventions transitioned into community settings (e.g., home, work, or school). During the transition periods, therapists provided support in work and/or school settings through job and/or study training, compensatory strategy implementation and generalization, as well as working as liaisons between the participants and their employers/teachers to facilitate accommodations and successful community integration. Caregiver participation involved a minimum of weekly family meetings with the participant's primary neuropsychologist and/or treatment team members as well as weekly caregiver support group meetings.

Descriptions of the types of CTN neurorehabilitation programs are beyond the scope of this paper (for more details, see Klonoff, 2010 and Klonoff, 2014). Briefly, the Home Independence Program focuses on improving the patient's ability to manage basic self-care and activities of daily living; increasing the amount of unsupervised time; enhancing independence with transportation needs; and exploring resources to engage in leisure and meaningful activities. The objectives of the Work and School Re-Entry Programs are to assist with the return to structured volunteer work, competitive employment, or school. The Refresher Program serves to update, review, and strengthen the compensatory strategies based on changes in the individual's circumstances (e.g., change in job, living situation, or medical condition) since his or her discharge from the above-mentioned programs.

\subsection{Recruitment and data collection}

For the commemoration of 30 years as a center, prior CTN patients, their caregivers, and community professionals were invited to a reunion and open house event at CTN in October 2016. Invitations to the event included information about the study and were mailed to at least 785 prior CTN program participants and their caregivers. The invitation was dispersed using multiple modalities (i.e., mail, phone, social media posts, brain injury support group newsletters, and email) to ensure that a maximum number of prior patient participants were informed about the event and the study. The St. Joseph's Hospital and Medical Center Institutional Review Board approved the study, and informed consent was obtained. Data collection was carried out in the following ways: (a) in-person in the clinic independently or with assistance from research staff; (b) over the phone with research staff; or (c) independently at remote locations using a website link. It is important to note that the long follow-up period resulted in difficulty reaching some of the prior CTN participants. Secondary to multiple factors, including but not limited to aging, illness, death, or change of residence, we were able to reach $13.6 \%$ of possible participants. This is similar to an 8 -year follow-up study, in which they were able to reach $17 \%$ of their patients with TBI who participated in their program (Ruet et al., 2019). 


\subsection{Primary outcome measures}

\subsubsection{Productivity status}

Productivity status of the participants was examined at the time of program admission, program discharge, and study participation. Similar to other studies examining long-term neurorehabilitation outcomes, the present study considered the following statuses to be productive: competitive employment (part-time or full-time); structured volunteer work (i.e., consistent with an employment schedule); participation in school; as well as a homemaker and childcare provider (Foy, 2014; Sarajuuri et al., 2005). Unemployment was considered unproductive. Study participants who were retired at the time of the study were removed from the productivity analysis.

\subsubsection{Driving status}

Driving status was measured as a dichotomous variable indicating whether or not the participants were driving at the time of program admission, program discharge, and study participation.

\subsection{Secondary outcome measures}

When examining community reintegration, Goranson and colleagues (2003) emphasized the importance of including measures of home independence and participation in community activities (e.g., financial management, psychosocial functioning, involvement in leisure activities) in addition to more common measures of productivity and driving. To incorporate these two types of outcome indicators, we used the following two scales to measure the functional status of the participants:

\subsubsection{Mayo-Portland Adaptability Inventory-4 (MPAI-4)}

Global functional outcome of the participants at the time of the study was assessed using the three MPAI-4 indices: Ability (range 0-47); Adjustment (range 0-46); and Participation (range 0-30). Based on their scores on the MPAI-4, the participants were categorized as follows: total score less than $30=$ good outcome; $30-40=$ mild limitations; $41-50=$ mild to moderate limitations; $51-60=$ moderate to severe difficulties; and above $60=$ severe limitations. Higher scores indicate lower functionality (Malec, 2005).

\subsubsection{Long-term outcome questionnaire ( $L O Q)$}

The LOQ was explicitly developed for the study to explore specific details related to the participants' level of independence in their community reintegration, which included the following domains: home management (e.g., who usually does grocery shopping, who usually prepares meals, who usually cares for children at home); financial independence (e.g., source(s) of income, annual income); quality of social life and engagement in leisure activities (e.g., do you have a best friend who is not your family member, how often do you meet people for fun outside your home, how often do you leave home to work, shop, or meet friends; do you attend brain injury support groups); and work-related functioning (e.g., what compensations are you using at your job or school). The LOQ contains 38 items including multiple choice, yes or no, and free response formats.

\subsection{Clinical and demographic variables}

Sociodemographic and clinical variables were extracted from the participants' medical records (Table 1). Of note, some data are missing from four participants' medical records. Table 2 provides the percentage of participants included in different follow-up periods.

Comparing the clinical and demographic variables between the four different follow-up periods listed in Table 2, study participants differed significantly on the variables of treatment duration and age at the time of the follow-up study. Post-hoc analyses showed the participants in the 0 to 5 -year group had a significantly longer treatment duration $(F(3$, $94)=7.69 ; p<0.001)$ and were significantly younger $(F(3,99)=8.78 ; p<0.001)$ than the participants in the $>10$ to 20 -year and $>20$ to 30 -year follow-up periods. Bonferroni correction was used to correct for multiple comparisons. Based on follow-up duration, there were no significant differences between the groups in terms of age at admission, age at time of injury, and duration from injury to admission.

\subsection{Statistical analysis}

Frequency analyses were performed to examine the proportion of participants who were productive and driving at three time points: (a) before starting neurorehabilitation; (b) at the time of discharge; and (c) at the time of this follow-up study. Frequency analyses were performed on the individual items of the LOQ to determine the participants' level of independence in managing their home, social life, leisure activities, and finances as well as their compensation use. Independent samples t-tests were performed 
Table 1

Clinical and demographic variables of the participants

\begin{tabular}{lcc}
\hline Variable $(n=107)$ & Mean (median) & Range \\
\hline Age at admission (years) & $35.81(14.52)$ & $15.3-73.3$ \\
Age at time of injury (years) & $33.24(15.78)$ & Infancy to 73.0 \\
Age at time of study (years) & $46.86(16.13)$ & $20.5-85.9$ \\
Injury to admission duration & $3.02(6.36)$ & 0 to 36.4 \\
$\quad$ years) & & \\
Discharge - Follow-up (years) & $9.47(7.81)$ & 0 to 29.3 \\
Treatment duration (months) & $12.22(6.52)$ & $1.9-29.9$ \\
Education at discharge (years) & $14.73(2.45)$ & 10.0 to 25.0 \\
Handedness (N=101) & $n$ & $\%$ \\
Right/Left & $94 / 7$ & $93 / 7$ \\
Gender (N=107) & $n$ & $\%$ \\
Male/Female & $65 / 42$ & $61 / 39$ \\
Ethnicity (N=107) & & \\
Caucasian & 82 & 77 \\
Hispanic & 10 & 9 \\
Other & 15 & 14 \\
Etiology (N=103) & & \\
TBI* & 62 & $60 \%$ \\
$\bullet$ Severe & 18 & $29 \%$ \\
$\bullet$ Moderate to Severe & 36 & $63 \%$ \\
$\bullet$ Mild & 3 & $5 \%$ \\
$\bullet$ N/A & 2 & $3 \%$ \\
CVA & 27 & $14 \%$ \\
Other (Anoxia, Tumor, \& & 14 & \\
Infection) & & \\
\end{tabular}

*TBI severity was rated based on the Glasgow coma scale (GCS) scores that were available for 34 participants. For those participants with a TBI who did not have GCS scores, the Mayo TBI severity classification system was applied to rate their level of injury severity (Malec et al., 2007).

Table 2

Distribution of participants in four follow-up periods

\begin{tabular}{lcc}
\hline Follow-up duration $(\mathrm{N}=103)$ & $n$ & Percentage \\
\hline Up to 5 years & 39 & 38 \\
$>5$ to 10 & 29 & 28 \\
$>10$ to 20 & 22 & 21 \\
$>20$ to 30 & 13 & 13 \\
\hline
\end{tabular}

to assess the relationship between functional independence (as measured by the MPAI-4) and driving status. Analyses of variance (ANOVA) were performed to explore the relationship between functional independence (as measured by the MPAI-4) and productivity status. Effect sizes are reported as Cohen's $d$. Bonferroni correction was used to adjust for multiple comparisons. Logistic regression analyses were performed to identify clinical, demographic, and outcome variables that predicted driving status at the time of study participation. The primary measure of the effect obtained from the logistic model consisted of the odds ratio (OR) and the consequent $95 \%$ confidence intervals (CIs). Two-tailed tests were used. The
SPSS (version 22) statistics package for Windows was used for performing statistical analyses.

\section{Results}

\subsection{Driving}

Among the available data, at the time of admission, $14(13.7 \%)$ out of 102 participants were driving; whereas at the time of discharge, $56(58.3 \%)$ of the 96 participants were driving; and impressively, at the time of the study $75(70.1 \%)$ out of 107 participants were driving.

One of the primary goals of this study was to examine the impact of driving status on the functional independence of the participants. To examine this relationship, participants were divided into driving and not-driving groups based on their driving status at the time of this study. The level of functional independence reported on the Abilities, Adjustment, and Participation indices of MPAI-4 between the driving and not-driving groups were compared using independent samples $t$-tests. The analyses revealed significant differences between the driving and not-driving groups on all three indices as well as the total MPAI-4 score (See Table 3; Abilities: $t(105)=4.40, p<0.001, d=0.43$; Adjustment: $t(105)=3.54, p<0.001, d=0.36$; Participation: $t(105)=5.72, p<0.001, d=0.53$; and Total score: $t(105)=4.20, p<0.001, d=0.42)$. It is noteworthy that there is a medium effect size for the variable of Participation and a small to medium effect size on the variables of Abilities, Adjustment, and Total scores (Cohen, 1988).

In a logistic regression, age $(\mathrm{OR}=1.05 ; 95 \%$ CI, $1.00-1.10 ; p=0.03)$, chronicity $(\mathrm{OR}=4.62 ; 95 \%$ CI, $1.52-14.07 ; p=0.007)$, and the MPAI-4 Ability scores $(\mathrm{OR}=0.93 ; 95 \% \mathrm{CI}, 0.89-0.98 ; p=0.01)$ all significantly predicted driving status such that increased age, chronicity within one year, and lower scores on the Ability subscale of the MPAI-4 were

Table 3

Relationship between driving status at the time of study and MPAI-4 scales

\begin{tabular}{lcc}
\hline $\begin{array}{l}\text { MAPI-4 } \\
\text { SCALES }\end{array}$ & $\begin{array}{c}\text { Driving } \\
(n=75) \mathrm{M}(\mathrm{SD})\end{array}$ & $\begin{array}{c}\text { Not driving } \\
(n=32) \mathrm{M}(\mathrm{SD})\end{array}$ \\
\hline Abilities & $36.17(13.15)$ & $47.94(11.46)$ \\
Adjustment & $32.94(13.20)$ & $42.28(10.57)$ \\
Participation & $24.55(15.47)$ & $42.38(12.97)$ \\
Total & $34.11(13.78)$ & $45.81(11.75)$ \\
\hline
\end{tabular}


associated with driving. The area under the curve for this model was $0.81 ; 95 \%$ CI $(0.72-0.91)$.

\subsection{Productivity}

At the time of program admission, only one (1\%) of 101 participants with available data was productive, that is, competitively employed. At the time of program discharge, $90(89 \%)$ participants out of the 101 with available data were productive (i.e., competitively employed, in school, volunteering, providing childcare, or homemakers). At the time of study participation, 84 (79\%) of the total 107 participants were productive: $69(65 \%)$ were competitively employed and/or in school; 15 (14\%) were homemakers, childcare providers and/or volunteers; $10(9 \%)$ were unemployed; and 13 (12\%) were retired.

After removing the $12 \%$ retired participants, analyses revealed that 69 (73\%) of the total 94 participants were competitively employed and/or in school; 15 (16\%) were homemakers, childcare providers and/or volunteers; and 10 (11\%) were unemployed. Based on their productivity status at the time of this study, the participants were divided into three groups: (1) work/school (part-/full-time competitive employment and/or school); (2) unpaid activities (volunteer, homemaker, childcare provider); and (3) unemployed. A one-way ANOVA showed a main effect of productivity status for MPAI-4 measures of Abilities $F(2,91)=3.09, p=0.05)$; Participation $F(2$, $91)=4.05, p=0.02)$; and Total score $F(2,91)=3.16$, $p=0.05$ ) (see Table 4). Post hoc analyses were carried out using the Fisher's least significant difference (LSD) procedure (which did not control for multiple comparisons) and revealed that the level of functioning was significantly higher for participants in group 1 (work/school) than for participants in group 3 (unemployed) on the MPAI-4 measures of Abilities $(p=0.02, d=0.87)$ and Participation $(p=0.02$, $d=0.84$ ) scores as well as the Total MPAI-4 score $(p=0.02, d=0.89)$. However, when corrected for multiple comparisons using the Bonferroni correction, there was only a tendency towards significant differences between group 1 (work/school) and group 3 (unemployed) on the Abilities $(p<0.06)$ and Participation $(p<0.06)$ scores as well as the Total MPAI-4 score $(p<0.07)$. Moreover, the level of functioning did not differ significantly between participants in group 2 (unpaid activities) and group 1 (work/school) or between group 2 and group 3 (unemployed; all $p$ values $>0.05$ ). Of note, a regression analysis was not conducted to identify the variables that pre-
Table 4

Means and standard deviations on the MPAI-4 scales based on productivity status

\begin{tabular}{lccc}
\hline MPAI-4 & $\begin{array}{c}\text { Work/school } \\
(n=69)\end{array}$ & $\begin{array}{c}\text { Unpaid } \\
\text { activity }(n=15)\end{array}$ & $\begin{array}{c}\text { Unemployed } \\
(n=10)\end{array}$ \\
\hline Abilities & $37.83(13.12)$ & $41.80(14.36)$ & $48.40(10.96)$ \\
Adjustment & $35.12(12.76)$ & $38.13(12.91)$ & $40.90(12.26)$ \\
Participation & $27.42(16.42)$ & $36.33(16.51)$ & $40.40(14.47)$ \\
Total & $35.86(14.19)$ & $40.87(13.05)$ & $46.50(8.32)$ \\
\hline
\end{tabular}

dicted the productivity status due to sample size limitations.

Based on the LOQ (see Table 5), among the 65 participants in group 1 (work/school), almost all of the study participants reported using one or more of the compensatory strategies that they were trained on during their neurorehabilitation (e.g., traditional or electronic datebook planners, note-taking, procedural checklists, accommodations, more time to complete tasks) at work or school. In terms of number of compensatory strategies, about three-quarters of the participants reported using multiple compensatory strategies while about one-quarter reported using only one compensatory strategy. Concerning the type of compensatory strategies, a sizeable proportion of the participants reported using a traditional or electronic datebook planner independently or in combination with procedural checklists, note-taking, and accommodations (e.g., more time to complete tasks) at work.

\subsection{Functional independence and psychosocial status}

The MPAI-4 was used to measure functional independence. The means and standard deviations of the MPAI-4 T-scores for all the participants are provided in Table 6. When the participants were categorized based on their Total score, 27 (25\%) reported good functioning with no limitations; 21 (20\%) reported functioning with mild limitations; 45 (42\%) reported functioning with mild to moderate limitations; 13 $(12 \%)$ reported functioning with moderate to severe limitations; and only $1(<1 \%)$ brain injury survivor reported functioning with severe limitations.

Other results of the LOQ provided insight into specific aspects of marital status, home management, financial independence, quality of social life, and engagement in leisure activities as well as participants' long term follow through with compensatory strategies learned during their neurorehabilitation (Table 5). About one-third of the participants were 
Table 5

Psychosocial Outcomes Measured Using LOQ

\begin{tabular}{|c|c|c|}
\hline Marital Status $(\mathrm{N}=107)$ & $n$ & $\%$ \\
\hline - Single & 36 & 33.7 \\
\hline - Married/engaged/relationship & 51 & 47.7 \\
\hline - Widowed & 4 & 3.7 \\
\hline - Separated/divorced & 16 & 15.0 \\
\hline \multicolumn{3}{|l|}{ Living Situation $(\mathrm{N}=107)$} \\
\hline - Lives alone & 22 & 20.6 \\
\hline - Lives with parents, family, or friends & 33 & 30.8 \\
\hline - Lives with significant other & 49 & 45.8 \\
\hline - Supported living environment & 3 & 2.8 \\
\hline \multicolumn{3}{|l|}{ Home Management (Independent; N = 107) } \\
\hline - Meal preparation & 32 & 30 \\
\hline - Grocery shopping & 38 & 36 \\
\hline \multicolumn{3}{|l|}{ Income bracket per year $(\mathrm{N}=91)$} \\
\hline$\bullet<20,000$ & 28 & 30 \\
\hline • 20,000-59,999 & 38 & 42 \\
\hline$\bullet>60,000$ & 25 & 28 \\
\hline \multicolumn{3}{|l|}{ Source of Income $(\mathrm{N}=107)$} \\
\hline - Work and others & 67 & 63 \\
\hline - Family/spouse/alimony & 16 & 15 \\
\hline $\begin{array}{l}\text { - Government, long-term disability, } \\
\text { workers' compensation }\end{array}$ & 20 & 19 \\
\hline - Retirement & 4 & 3 \\
\hline \multicolumn{3}{|l|}{ Has a friend to confide $(\mathrm{N}=107)$} \\
\hline - Yes & 81 & 75.7 \\
\hline$\bullet$ No & 26 & 24.3 \\
\hline \multicolumn{3}{|l|}{ Social Activities $(\mathrm{N}=107)$} \\
\hline - At least once a week & 61 & 57.0 \\
\hline - At least once a month & 29 & 27.1 \\
\hline - Rarely to None & 17 & 15.9 \\
\hline \multicolumn{3}{|c|}{ Leaves home for work or other purposes $(\mathrm{N}=105)$} \\
\hline - Almost everyday & 54 & 51.4 \\
\hline - 3-5 times per week & 25 & 23.8 \\
\hline - $1-2$ times per week & 15 & 14.3 \\
\hline - Less than once a week & 11 & 10.5 \\
\hline \multicolumn{3}{|c|}{ Challenges Engaging in Social Activities $(\mathrm{N}=107)$} \\
\hline - Yes & 33 & 30.8 \\
\hline$\bullet \mathrm{No}$ & 74 & 69.2 \\
\hline \multicolumn{3}{|l|}{ Who plans social activities $(\mathrm{N}=107)$} \\
\hline - Self & 26 & 24.3 \\
\hline - Self and someone else & 72 & 67.3 \\
\hline - Someone else & 9 & 8.4 \\
\hline \multicolumn{3}{|l|}{$\begin{array}{l}\text { Compensation use of participants that returned } \\
\text { to work and/or school }(\mathrm{N}=69)\end{array}$} \\
\hline - Participants using compensations & 65 & 94.2 \\
\hline - One compensatory strategy & 18 & 28.1 \\
\hline - Two compensatory strategies & 15 & 23.4 \\
\hline - Three to four compensatory strategies & 28 & 43.8 \\
\hline - Five compensatory strategies & 3 & 4.7 \\
\hline - Datebook and others & 53 & 82.8 \\
\hline
\end{tabular}

Table 6

MPAI-4 scores of all the participants at the time of this follow-up study

\begin{tabular}{lccc}
\hline $\begin{array}{l}\text { MPAI-4 INDEX } \\
\text { SCALES }(\mathrm{N}=107)\end{array}$ & Mean & SD & Category \\
\hline Abilities & 39.69 & 13.73 & Mild limitations \\
Adjustment & 35.74 & 13.14 & Mild limitations \\
Participation & 29.88 & 16.84 & Good Outcome \\
Total & 37.61 & 14.21 & Mild limitations \\
\hline
\end{tabular}

single at follow-up; about one-half were married, engaged, or in a relationship. With regard to their living situation, it is noteworthy that only about $3 \%$ of the participants lived in supported living settings. Approximately one-third of the participants were able to manage their meal preparation and grocery shop independently. In terms of financial independence, more than two-thirds of the participants made more than $\$ 20,000$ per year and relied solely on their employment or retirement for their income. Regarding participation in social and leisure activities, three-quarters of the participants endorsed having a friend to confide in.

Most participants (more than two-thirds) denied problems engaging in social activities and endorsed actively making their own plans. More than half of the sample participated in social activities once a week and about one-quarter were involved in social activities at least once a month. Interestingly, three-quarters of the participants left their homes for work or other purposes at least three to five times per week.

\subsection{Chronicity}

Based on the duration between the time of injury and time of admission to the center, the sample was divided into acute (one year or less than one year since the brain injury) and chronic (more than one year since the brain injury) groups. There was no significant effect of chronicity on clinical and demographic variables (see Table 7).

With regard to outcome variables, there was no significant main effect of chronicity on productivity status of the participants at the time of the study. However, there was a significant effect of chronicity on the level of functional independence measured using the MPAI-4 index scales and total score. The acute group experienced significantly fewer limitations than the chronic group, Abilities: $t(102)=3.84 ; p<0.001, d=0.78$; Adjustment: $t(102)=3.37, p<0.001, d=0.68$; Participation: $t(102)=4.98, p<0.001, d=1.01$; and Total score: $t(102)=3.62, p<0.001, d=0.73$.

\section{Discussion}

The present study assessed the long-term productivity status, driving status, and psychosocial functioning of individuals with ABI who completed holistic milieu-oriented neurorehabilitation up to 30 years ago. The study participants had heterogeneous 
Table 7

Relationship between chronicity and clinical, demographic, as well as MPAI-4 scales

\begin{tabular}{lccr}
\hline Variable $(n=102)$ & $\begin{array}{c}\text { Acute }(\leq 1 \text { year }) \\
\text { Mean }(\mathrm{SD})(n=60)\end{array}$ & $\begin{array}{c}\text { Chronic }(>1 \text { year }) \\
\text { Mean }(\mathrm{SD})(n=42)\end{array}$ & $t$ \\
\hline Age at admission (years) & $36.30(15.44)$ & $35.11(13.27)$ & 0.41 \\
Age at time of injury (years) & $35.51(15.63)$ & $29.39(15.41)$ & 1.93 \\
Age at time of study (years) & $45.89(17.22)$ & $45.99(13.88)$ & 0.03 \\
Discharge - Follow-up (years) & $8.89(6.90)$ & $9.90(8.67)$ & 0.66 \\
Treatment duration (months) & $12.21(6.81)$ & $12.25(6.14)$ & 0.03 \\
MPAI-4 Abilities* & $35.72(13.25)$ & $45.76(12.66)$ & 3.84 \\
MPAI-4 Adjustment* & $32.32(12.43)$ & $40.81(12.69)$ & 3.37 \\
MPAI-4 Participation* & $23.93(15.1)$ & $43.02(13.96)$ & 4.96 \\
MPAI-4 Total* & $33.55(13.76)$ & & 3.62 \\
${ }^{*} p<0.001$. & & &
\end{tabular}

neurological etiologies (almost two-thirds had TBIs, one-quarter had cerebrovascular conditions, and the rest had other types of diagnoses); variable durations of time between injury and treatment initiation $(59 \%$ of the sample were less than one year post-injury and $41 \%$ were over one year post-injury); as well as differing follow-up durations (i.e., a few weeks to 29 years after discharge).

The results of this study demonstrate that the rate of return to driving increased dramatically from the time of program admission to discharge; importantly, the rates continued to grow further at extended follow-up periods. Our results are congruent with other long-term outcome studies reporting similar results at the time of discharge with rates increasing considerably at longer follow-up periods (Klonoff et al., 2006; Novack et al., 2010; Olver et al., 1996; Ponsford et al., 2014). Additionally, our findings regarding the positive influence of driving on functional independence have been supported by several previous studies (Novack et al., 2010; Rapport, Bryer, \& Hanks, 2008). It is encouraging that the results illustrate that survivors of $\mathrm{ABI}$ with moderate to severe injuries can continue to progress in their ability to drive even after completing formal neurorehabilitation. In light of these findings, ABI survivors would be best served by considering safe and systematic treatment interventions facilitating their return to driving many years post-discharge. Thus, clinicians should consider referring ABI survivors to rehabilitation services addressing driving skills (e.g., an adaptive driving evaluation) in chronic phases of recovery, even if they have not received formal treatment for many years.

In terms of productivity, a large proportion (79\%) of participants in this study endorsed leading active lives up to 30 years post-discharge; $73 \%$ were competitively employed or in school. Taking the $12 \%$ retired participants into account, the productivity rate of the present sample is fairly comparable to previous outcome studies evaluating holistic neurorehabilitation: $89 \%$ at the 2-year follow-up involving individuals with TBI (Sarajuuri et al., 2005); 88\% at up to 11-years post-discharge including individuals with TBI (Klonoff et al., 2000); and $84 \%$ at up to 11-years post-discharge including individuals with ABI (Klonoff et al., 2001). On the other hand, the findings show more favorable outcomes than studies assessing individuals who did not complete holistic comprehensive neurorehabilitation (Colantonio et al., 2004; Ponsford et al., 2014). It is noteworthy that the majority of the participants working or in school reported using the compensatory strategies learned during treatment. We speculate that holistic neurorehabilitation approaches enabling generalization of compensatory strategies to specific work/school settings (e.g., work trials) may have helped the participants use them on a long-term basis, thereby maintaining their productivity.

In the present study, self-reported psychosocial functioning of ABI survivors assessed using the MPAI-4 scores (i.e., Abilities, Adjustment, Participation, and Total) at follow-up is comparable or better than previous studies (Altman, Swick, \& Malec, 2013; Altman, Swick, Parrot, \& Malec, 2010; Eicher, Murphy, Murphy, \& Malec, 2012; Malec \& Kean, 2016). Additionally, positive findings emerged from the LOQ in the domains of marital status, independent living, financial independence, and social functioning, including friendships and community involvement. In terms of romantic relationships, our findings are fairly comparable to those obtained from a 10-year post-injury outcome study (Ponsford et al., 2014) and more positive than those obtained from a 1-7 year post-discharge outcome study (Klonoff et al., 2006). It is thought that the emphasis placed on family support and education in holistic comprehensive programs contributes to relationship stability. 
Most of the study participants were independent in their living situation with or without others $(97.2 \%)$, with only a very small percentage in a supported living environment. However, about two-thirds of the sample reported needing assistance with meal preparation and grocery shopping. Income data revealed positive findings with less than one-third of the sample earning less than $\$ 20,000$ per year and only about one-fifth relying on external supports (e.g., government, long-term disability, or workers' compensation), as expected based on the productivity results. Skills and compensatory strategies required for home and community independence are a major focus of holistic neurorehabilitation programs, and these results suggest enduring benefits.

From a social standpoint, most of the sample reported having close friendships, being able to plan and be involved in social activities with others, and accessing social resources. These findings support prior reports of psychosocial adjustment with holistic neurorehabilitation (Cicerone et al., 2019) in contrast to prior reports of loneliness in patients without holistic neurorehabilitation (Hoofien, Gilboa, Vakil, \& Donovick, 2001). Of note, the intervention in the present study emphasized specific social and interpersonal skills as well as exposure to renewed and novel community activities that accommodated neurological deficits through recreational therapy.

In the present study, participants who entered the holistic neurorehabilitation within the first year of their brain injury outperformed those who began later in their recovery process in terms of driving and functional independence. There are several studies that support the advantages of individuals with TBI or stroke receiving treatment in the earlier stages of recovery (Cicerone et al., 2019; Hayden et al., 2013; León-Carrión et al., 2013; Micklewright, Yutsis, Smigielski, Brown, \& Bergquist, 2011). Despite the influence of chronicity on driving and psychosocial functioning, this variable did not affect productivity outcomes. We speculate this may be because productivity goals are continuous and can be modified based on neurological deficits and productivity exists on a spectrum (e.g., different positions require variable skills, physical abilities, hours, etc.), whereas driving is a discrete, dichotomous variable (i.e., the individual can or cannot drive). Similar to other studies, participants in the present study achieved their productivity goals whether they entered neurorehabilitation before or later than one year after their ABI (High et al., 2006; Hylin et al., 2017; Kleim \& Jones, 2008; Trudel et al., 2007). In the holistic neuroreha- bilitation treatment model, participants were guided in identifying realistic goals, which enabled them to resume productive activities, even if their new roles were quite different than their pre-injury productive positions.

This study had some valid limitations. Due to the long-term follow-up duration, the rate of participation is relatively low. Taking part in this study depended on receiving the invitation and consenting to participate. Among those who were reachable, the participants self-selected to join the study. It is possible that survivors who perceived their rehabilitation experience and outcome to be positive may have been more likely to participate than those who had other types of perceptions. Lack of a baseline assessment for the psychosocial outcome measure (MPAI-4) limits the ability to assess any changes in functional independence since program discharge. Comprehensive holistic neurorehabilitation programs comprise numerous components, making it difficult to identify specific treatment factors that generate clinically significant change. Given the heterogeneity of the sample and lack of randomization and control group, the findings may have limited generalizability. It would be beneficial for future studies to (1) focus on neurorehabilitation outcome of specific diagnoses to improve the homogeneity of the sample, (2) design studies with randomization to treatment and control groups, (3) collect pre-treatment, post-treatment, as well as follow-up data, and (4) conduct dismantling research to identify effective components of treatment programs.

\section{Conclusion}

This outcome study demonstrates the positive and enduring benefits of holistic neurorehabilitation programs for enhancing the independence, driving, productivity, and quality of life of survivors of ABI up to 30 years after discharge. Additionally, findings related to chronicity underscore the importance of recognizing the potential of survivors of $A B I$ to benefit from intensive holistic treatment up to many years post-injury.

\section{Acknowledgments}

The study was supported by a research grant from Giles W. and Elise G. Mead Foundation. The authors would like to gratefully acknowledge Edward Kober- 
stein for assistance with manuscript preparation. The authors thank the staff of Neuroscience Publications at Barrow Neurological Institute for assistance with manuscript preparation.

\section{Conflict of interest}

None to report.

\section{References}

Altman, I. M., Swick, S., \& Malec, J. F. (2013). Effectiveness of home- and community-based rehabilitation in a large cohort of patients disabled by cerebrovascular accident: Evidence of a dose-response relationship. Archives of Physical Medicine and Rehabilitation, 94(9), 1837-41.

Altman, I. M., Swick, S., Parrot, D., \& Malec, J. F. (2010). Effectiveness of community-based rehabilitation after traumatic brain injury for 489 program completers compared with those precipitously discharged. Archives of Physical Medicine and Rehabilitation, 91(11), 1697-704.

Andelic, N., Arango-Lasprilla, J. C., Perrin, P. B., Sigurdardottir, S., Lu, J., Landa, L. O., Forslund, M. V., \& Roe, C. (2016). Modeling of Community Integration Trajectories in the First Five Years after Traumatic Brain Injury. Journal of Neurotrauma, 33(1), 95-100.

Arwert, H. J., Schults, M., Meesters, J. J. L., Wolterbeek, R., Boiten, J., \& Vliet Vlieland, T. (2017). Return to work 2-5 years after stroke: A cross-sectional study in a hospital-based population. Journal of Occupational Rehabilitation, 27(2), 239-46.

Cattelani, R., Zettin, M., \& Zoccolotti, P. (2010). Rehabilitation treatments for adults with behavioral and psychosocial disorders following acquired brain injury: A systematic review. Neuropsychology Review, 20(1), 52-85.

Cicerone, K. D., Goldin, Y., Ganci, K., Rosenbaum, A., Wethe, J. V., Langenbahn, D. M., Malec, J. F., Bergquist, T. F., Kingsley, K., Nagele, D., Trexler, L., Fraas, M., Bogdanova, Y., \& Harley, J. P. (2019). Evidence-based cognitive rehabilitation: Systematic review of the literature from 2009 through 2014. Archives of Physical Medicine and Rehabilitation, doi: 10.1016/j.apmr.2019.02.011. [Epub ahead of print].

Cicerone, K. D., Langenbahn, D. M., Braden, C., Malec, J. F., Kalmar, K., Fraas, M., Felicetti, T., Laatsch, L., Harley, J. P., Bergquist, T., Azulay, J., Cantor, J., \& Ashman, T. (2011). Evidence-based cognitive rehabilitation: updated review of the literature from 2003 through 2008. Archives of Physical Medicine and Rehabilitation, 92(4), 519-30.

Cicerone, K. D., Mott, T., Azulay, J., Sharlow-Galella, M. A., Ellmo, W. J., Paradise, S., \& Friel, J. C. (2008). A randomized controlled trial of holistic neuropsychological rehabilitation after traumatic brain injury. Archives of Physical Medicine and Rehabilitation, 89(12), 2239-49.

Cohen, J. (1988). Statistical Power Analysis for the Behavioral Sciences (2nd ed.). Hillsdale, NJ: Lawrence Erlbaum Associates.

Colantonio, A., Ratcliff, G., Chase, S., Kelsey, S., Escobar, M., \& Vernich, L. (2004). Long-term outcomes after moderate to severe traumatic brain injury. Disability and Rehabilitation, 26(5), 253-61.

Eicher, V., Murphy, M. P., Murphy, T. F., \& Malec, J. F. (2012). Progress assessed with the Mayo-Portland Adaptability Inventory in 604 participants in 4 types of post- inpatient rehabilitation brain injury programs. Archives of Physical Medicine and Rehabilitation, 93(1), 100-107.

Forslund, M. V., Perrin, P. B., Røe, C., Sigurdardottir, S., Hellstrøm. T., Berntsen, S. A., Lu, J., Arango-Lasprilla, J. C., \& Andelic, N. (2019). Global outcome trajectories up to 10 years after moderate to severe traumatic brain injury. Frontiers in Neurology, 10(219), doi: 10.3389/fneur.2019.00219. eCollection 2019.

Foy, C. M. (2014). Long term efficacy of an integrated neurological and vocational rehabilitation programme for young adults with acquired brain injury. Journal of Occupational Rehabilitation, 24(3), 533-42.

Geurtsen, G. J., Martina, J. D., van Heugten, C. M., \& Geurts, A. C. H. (2008). A prospective study to evaluate a new residential community reintegration programme for severe chronic brain injury: The Brain Integration Programme. Brain Injury, 22(78), 545-54.

Geurtsen, G. J., van Heugten, C. M., Martina, J. D., Rietveld, A. C., Meijer, R., \& Geurts, A. C. H. (2011). A prospective study to evaluate a residential community reintegration program for patients with chronic acquired brain injury. Archives of Physical Medicine and Rehabilitation, 92(5), 696-704.

Goranson, T. E., Graves, R. E., Allison, D., \& La Freniere, R. (2003). Community integration following multidisciplinary rehabilitation for traumatic brain injury. Brain Injury, 17(9), 759-74.

Hayden, M. E., Plenger, P., Bison, K., Kowalske, K., Masel, B., \& Qualls, D. (2013). Treatment effect versus pretreatment recovery in persons with traumatic brain injury: A study regarding the effectiveness of postacute rehabilitation. $P M \& R, 5(4), 319$ 27.

High, W. M. Jr., Roebuck-Spencer, T., Sander, A. M., Struchen, M. A., \& Sherer, M. (2006). Early versus later admission to post-acute rehabilitation: impact on functional outcome after traumatic brain injury. Archives of Physical Medicine and Rehabilitation, 87(3), 334-42.

Hoofien, D., Gilboa, A., Vakil, E., \& Donovick, P. J. (2001). Traumatic brain injury (TBI) 10-20 years later: A comprehensive outcome study of psychiatric symptomatology, cognitive abilities and psychosocial functioning. Brain Injury, 15(3), 189-209.

Hylin, M. J., Kerr, A. L., \& Holden, R. (2017). Understanding the Mechanisms of Recovery and/or compensation following Injury. Neural Plasticity, 2017(7125057), http://dx.doi.org/10.1155/2017/7125057.

Kleim, J. A., \& Jones, T. A. (2008). Principles of experiencedependent neural plasticity: Implications for rehabilitation after brain damage. Journal of Speech, Language, \& Hearing Research, 51(1), S225-S239.

Klonoff, P. S. (2010). Psychotherapy after brain injury: Principles and techniques. New York: Guilford press.

Klonoff, P. S. (2014). Psychotherapy for families after brain injury. New York: Springer Science+Business Media.

Klonoff, P. S. (2015). Dilemmas and innovations in team dynamics for modern holistic milieu therapy: A 30-year retrospective review. Neuro-Disability \& Psychotherapy, 3(2), 93-127. 
Klonoff, P. S., Lamb, D. G., \& Henderson, S. W. (2000). Milieubased neurorehabilitation in patients with traumatic brain injury: Outcome at up to 11 years postdischarge. Archives of Physical Medicine and Rehabilitation, 81(11), 1535-37.

Klonoff, P. S., Lamb, D. G., \& Henderson, S. (2001). Outcomes from milieu-based neurorehabilitation at up to 11 years postdischarge. Brain Injury, 15(5) 413-28.

Klonoff, P. S., Olson, K. C., Talley, M. C., Husk, K. L., Myles, S. M., Gehrels, J., \& Dawson, L. K. (2010). The relationship of cognitive retraining to neurological patients' driving status: The role of process variables and compensation training. Brain Injury, 24(2), 63-73.

Klonoff, P. S., Talley, M. C., Dawson, L. K., Myles, S. M., Watt, L. M., Gehrels, J. A., \& Henderson, S. W. (2007). The relationship of cognitive retraining to neurological patients' work and school status. Brain Injury, 21(11), 1097-107.

Klonoff, P. S., Watt, L. M., Dawson, L. K., Henderson, S. W., Gehrels, J. A., \& Wethe, J. V. (2006). Psychosocial outcomes 1-7 years after comprehensive milieu-oriented neurorehabilitation: The role of pre-injury status. Brain Injury, 20(6), 601-12.

León-Carrión, J., Domínguez-Morales, M. R., \& Martin, J. M. (2005). Driving with cognitive deficits: Neurorehabilitation and legal measures are needed for driving again after severe traumatic brain injury. Brain Injury, 19(3), 213-19.

León-Carrión, J., Machuca-Murga, F., Solís-Marcos, I., LeónDomínguez, U., \& Domínguez-Morales, M.del.R. (2013). The sooner patients begin neurorehabilitation, the better their functional outcome. Brain Injury, 27(10), 1119-23.

Malec, J. F. (2005). The Mayo Portland Adaptability Inventory. The Center for Outcome Measurement in Brain Injury. http://www.tbims.org/combi/mpai (accessed May 23, 2019).

Malec, J. F. (2001). Impact of comprehensive day treatment on societal participation for persons with acquired brain injury. Archives of Physical Medicine and Rehabilitation, 82(7), 88595.

Malec, J. F., Brown, A. W., Leibson, C. L., Flaada, J. T., Mandrekar, J. N., Diehl, N. N., \& Perkins, P. K. (2007). The Mayo classification system for traumatic brain injury severity. Journal of Neurotrauma, 24(9), 1417-24.

Malec, J. F., \& Kean, J. (2016). Post-inpatient brain injury rehabilitation outcomes: Report from the National OutcomeInfo Database. Journal of Neurotrauma, 33(14), 1371-79.
Micklewright, J. L., Yutsis, M., Smigielski, J. S., Brown, A. W., \& Bergquist, T. F. (2011). Point of entry and functional outcomes after comprehensive day treatment participation. Archives of Physical Medicine and Rehabilitation, 92(12), 1974-78.

Novack, T. A., Labbe, D., Grote, M., Carlson, N., Sherer, M., Arango-Lasprilla, J. C., Bushnik, T., Cifu, D., Powell, J. M., Ripley, D., \& Seel, R. T. (2010). Return to driving within 5 years of moderate-severe traumatic brain injury. Brain Injury, 24(3), 464-71.

Olver, J. H., Ponsford, J. L., \& Curran, C. A. (1996). Outcome following traumatic brain injury: A comparison between 2 and 5 years after injury, Brain Injury, 10(11), 841-48.

Perumparaichallai, R. K., Husk, K. L., Myles, S. M., \& Klonoff, P. S. (2014). The relationship of neuropsychological variables to driving status following holistic neurorehabilitation. Frontiers in Neurology, 5(56), doi: 10.3389/fneur.2014.00056.

Ponsford, J. L., Downing, M. G., Olver, J., Ponsford, M., Acher, R., Carty, M., \& Spitz, G. (2014). Longitudinal follow-up of patients with traumatic brain injury: Outcome at two, five, and ten years post-injury. Journal of Neurotrauma, 31(1), 64-77.

Rapport, L. J., Bryer, R. C., \& Hanks, R. A. (2008). Driving and community integration after traumatic brain injury. Archives of Physical Medicine and Rehabilitation, 89(5), 922-30.

Ruet, A., Bayen, E., Jourdan, C., Ghout, I., Meaude, L., Lalanne, A., Pradat-Diehl, P., Nelson, G., Charanton, J., Aegerter, P., Vallat-Azouvi, C., \& Azouvi, P. (2019). A detailed overview of long-term outcomes in severe traumatic brain injury eight years post-injury. Frontiers in Neurology, 10(120), doi: 10.3389/fneur.2019.00120.

Sander, A. M., Clark, A., \& Pappadis, M. R. (2010). What is community integration anyway? Defining meaning following traumatic brain injury. Journal of Head Trauma Rehabilitation, 25(2), 121-27.

Sarajuuri, J. M., Kaipio, M.-L., Koskinen, S. K., Niemelä, M. R., Servo, A. R., \& Vilkki, J. S. (2005). Outcome of a comprehensive neurorehabilitation program for patients with traumatic brain injury. Archives of Physical Medicine and Rehabilitation, 86(12), 2296-302.

Trudel, T. M., Nidiffer, F. D., \& Barth, J. T. (2007). Communityintegrated brain injury rehabilitation: Treatment models and challenges for civilian, military, and veteran populations. Journal of Rehabilitation Research and Development, 44(7), 1007-1016. 